Another drey about half a mile away, in the same wood, was found to contain a black female suckling a single black young one.

Grey squirrels were first introduced into Woburn by the late Duke of Bedford in 1890. The black phase was introduced later, but unfortunately there is no record of the numbers involved, nor of the locality from which the introduction was made.

Melanic grey squirrels have been recorded from Ontario, the Alleghanies of Pennsylvania, New Brunswick, Michigan and Minnesota. They are stated to occur locally, and to be confined to narrow limits. All these areas are included in the range of one subspecies of Sciurus carolinensis, namely, carolinensis leucotis Gapper. It is possible that the melanism occurs only in this sub-species; in which case the grey squirrel population of Great Britain includes the leucotis form. In Great Britain melanics are found also at Ashwell and Northchurch in Hertfordshire ${ }^{2}$.

The Continental red squirrel (Sciurus vulgaris L.) has a melanic form, which has been noted in large numbers in many parts of its range. Neither case has been analysed genetically.

A degree of variation is found in the melanic forms of both species. Melanic grey squirrels were found with brown underparts, or with the hairs of the back tipped with brown. One specimen had a streak of white on the belly. The saturation of melanism appears to be slight enough to be affected by variation of the rest of the gene complex.

Dr. E. B. Ford, of the Department of Zoology and Comparative Anatomy, University of Oxford, and Mr. C. Elton, director of this Bureau, kindly gave advice in this matter. The Duke of Bedford was asked for details of the introductions into Woburn.

Bureau of Animal Population,

Monrca Shorten.

University Museum,

Oxford.

May 1.

${ }^{2}$ Nelson, E. W., Nat. Geog. Mag., 33, 371 (1918).

'Trans. Herts Nat. Hist. Soc. Field Club, 22, 53.

\section{Heterokaryosis and the Mating-Type Factors in Neurospora}

EXPERIMENTS on the production of heterokaryosis in Neurospora have disclosed a striking difference, in the relationship of mating type to heterokaryosis, between the homothallic species $N$. tetrasperma and the heterothallic species $N$. Crassa.

Hansen and Smith ${ }^{1}$ have demonstrated the occurrence of heterokaryosis, that is, the presence of genetically different nuclei within individual cells of a mycelium, in Fungi Imperfecti. More recently this phenomenon has been discovered and investigated in Neurospora ${ }^{2,3,4}$.

The heterothellic species $N$. crassa and $N$. sitophila each consist of two mating types which are separated at the time of ascospore formation. Single ascospore cultures only produce functional perithecia when brought into contact with cultures of the different mating type. $N$. tetrasperma also possesses two mating types; but in this species, the ascospore is bi-nucleate at its inception, one nucleus containing one of the mating-type or incompatibility factors, the second nucleus containing the opposite factor. A single ascospore culture is therefore heterokaryotic and selffertile. Homokaryotic lines can be obtained, however, which contain only one or other of the matingtype factors and which do not form functional perithecia unless brought into contact with the different mating-type ${ }^{5}$. Dodge ${ }^{3}$ found that, when a certain homokaryotic race of dwarf habit was combined with another race of poor vigour, a heterokaryon was produced showing much greater vegetative vigour than either of the parent races. This occurred whether the second race was of the same or different mating type from the original dwarf.

Beadle and Coonradt4, working chiefly with mutants of $N$. crassa characterized by their inability to grow well in the absence of certain specific chemical compounds, obtained similar results. When two such deficient mutants were combined, they produced a heterokaryon which was able to grow at the normal rate in the absence of the substances required by the individual lines. There is thus a 'dominance' effect of the normal allele in one nucleus over the mutant allele in the other. These results, however, were obtained only when mutants of the same mating type were combined. Beadle and Coonradt suggest that the absence of this vegetative vigour when mutants of different mating type are combined is due to the tendency of such combinations to form perithecia rather than to grow in a vegetative manner.

Using mutants derived from the fluffy strain of $N$. crassa, I have made many such combinations, using mutants characterized by reduced vigour. In most instances, when the two components belong to the same mating type, a heterokaryon is produced approaching and often equalling the standard fluffy type in vigour. When the mutants are of different mating types, the two mycelia grow side by side or the more vigorous overgrows the other, without any evidence of heterokaryosis whatever. All attempts so far to obtain evidence of heterokaryosis involving nuclei of the two different mating types (which will be described elsewhere) have failed. It is not yet known whether the fusion of hyphr containing such nuclei is inhibited or whether such fusion occurs but without the two types of nuclei becoming associated.

These results are taken to indicate that the association of nuclei of different mating types occurs at the time of sexual reproduction and not by fusion of vegetative hyphæ.

The difference between a homothallic species such as $N$. tetrasperma and a heterothallic species such as $N$. crassa appears to be that, in the former, nuclei containing the mating-type factors are attracted at all stages in their life-history, whereas in the latter they are repelled or kept apart until the time of sexual reproduction, as suggested by Dodge ${ }^{6}$.

Department of Cryptogamic Botany, Eva Sansome. University, Manchester. May 23.

1 Hansen, H. N., and Smith, R. E., Phytopath., 22, 953 (1932). Iindgren, C. C., J. Genet., 28, 425 (1934).

Dodge, B. O., Bull. Torrey Bot. Club, 69, 75 (1942).

- Beadle, G. W., and Coonradt, V. L., Genetics, 29, 291 (1944).

- Dodge, B. O., Mycologia, 20, 226 (1928).

- Dodge, B. O., Mycologia, 27, 418 (1935). 